\title{
Transformation to small-cell carcinoma as an acquired resistance mechanism to AZD9291: A case report
}

\author{
Lin $\mathrm{Li}^{1}$, Hui Wang ${ }^{1}$, Chao $\mathrm{Li}^{1}$, Zheng Wang ${ }^{2}$, Ping Zhang ${ }^{1}$ and Xu Yan ${ }^{1}$ \\ ${ }^{1}$ Department of Oncology, Beijing Hospital, National Center of Gerontology, Beijing, China \\ ${ }^{2}$ Department of Pathology, Beijing Hospital, National Center of Gerontology, Beijing, China \\ Correspondence to: Lin Li, email: lilin_51@hotmail.com \\ Keywords: NSCLC; EGFR-TKI; AZD9291; acquired resistance; transformation \\ Received: October 11,2016 Accepted: December 27, $2016 \quad$ Published: January 04, 2017
}

\section{ABSTRACT}

\begin{abstract}
AZD9291, a third-generation epidermal growth factor receptor (EGFR) tyrosine kinase inhibitor (TKI), benefits patients with T790M mutant non-small-cell lung cancer who fail treatment with first-generation EGFR TKIs. Acquisition of resistance to AZD9291 occurs inevitable and mechanisms need to be explored. We reported an advanced lung adenocarcinoma female with EGFR exon19 deletion treated on AZD9291 after failure of erlotinib and chemotherapy. Disease progressed again after 6 months' treatment of AZD9291 with hepatic metastasis. Re-biopsy of the hepatic lesion showed histopathology transformation to small cell lung cancer, which harbored EGFR exon19 deletion. Therefore, small cell carcinoma transformation is one of potential resistance mechanisms to AZD9291 and regimen for small cell carcinoma may be one of the treatment options.
\end{abstract}

\section{INTRODUCTION}

Epidermal growth factor receptor (EGFR) tyrosine kinase inhibitors (TKIs) play very important roles in treatment of advanced EGFR mutated non-small cell lung cancer (NSCLC). However, acquired resistance may develop inevitably, and T790M mutation accounts for approximately $60 \%$ of the resistance cases in firstgeneration TKIs treatment $[1,2]$. Third-generation TKIs such as AZD9291 were effective against T790M mutated NSCLC, with overall response rate (ORR) of about $60 \%$, but acquired resistance occur in about 10 months [3]. The mechanisms of acquired resistance to thirdgeneration TKIs need to be explored. Here we reported a case of small cell lung cancer (SCLC) transformation post AZD9291 treatment as a resistance mechanism.

\section{CASE REPORT}

A 52-year-old non-smoker female was first detected a $2 \mathrm{~cm}$ mass in right upper lobe of lung with computed tomography (CT) scan in May, 2014. She then underwent right upper lobectomy with regional lymph node dissection. The pathology diagnosis was adenocarcinoma with multiple metastasized lymph nodes in group 2 (9/9), group $4(4 / 4)$, group $7(7 / 7)$, group $9(0 / 1)$ and group 10 (6/6) (Figure 1). EGFR exon19 deletion was detected by amplification refractory mutation system (ARMS). The patient was diagnosed as adenocarcinoma in right upper lobe, staged $\mathrm{T}_{2} \mathrm{~N}_{2} \mathrm{M}_{0}$ (IIIA). She received adjuvant chemotherapy with gemcitabine plus cisplatin. However, multiple micronodules were found in bilateral lung after finishing two cycles of chemotherapy. Then she started treatment on erlotinib from Sep, 2014 and achieved partial response in one month. Regular CT examination was underwent every two months, and new bilateral lung lesions were found in Aug, 2015, after 11 months treatment of erlotinib. Because of the difficulty of re-biopsy, plasma circulating tumor DNA (ctDNA) was collected for EGFR mutation detection by ARMs. However, neither exon19 deletion nor T790M mutation was detected. The patient was given chemotherapy with pemetrexed plus nedaplatin. But disease progressed after two cycles. Then docetaxol plus bevacizumab was given but disease progressed again. Meanwhile, she had symptoms of cough and shortness of breath. Then she was on AZD9291 in Dec, 2015 after chemotherapy failure. The patient's symptoms improved dramatically in one month and CT scan showed disease improved obviously (Figure 2). She continued on treatment of AZD9291 until multiple hepatic lesions appeared in May, 2016 (Figure 3), while the lesions of lung were still stable. Liver biopsy was performed and histologic analysis showed as small cell 
lung cancer. Immunohistochemistry staining confirmed as strong positive for synaptophysin (Figure 4). ARMs analysis showed EGFR exon19 deletion, without T790M mutation. Because there were not sufficient tissue left for next generation sequencing assay (NGS) test, peripheral ctDNA was tested and detected mutations of EGFR exon19 deletion, P53 exon6 V203L-pTEN exon4 NC82 and PIK3CA exon10 E545Q. The level of the patient's neuronspecificenolase (NSE) was $113.8 \mathrm{ng} / \mathrm{ml}$, which was $13 \mathrm{ng} / \mathrm{ml}$ in Dec, 2015 before treatment of AZD9291. Then the patient was treated on etopside and carboplatin in addition to AZD9291. Her NSE level decreased from $113.8 \mathrm{ng} / \mathrm{ml}$ to $28 \mathrm{ng} / \mathrm{ml}$ after one cycle of chemotherapy and then to $10 \mathrm{ng} / \mathrm{ml}$ after the second cycle. The CT examination after two cycles of chemotherapy showed smaller hepatic lesions but did not reach partial response. Now the patient was on further treatment and followed up.

\section{DISCUSSION}

AZD9291 is one of the third-generation TKIs capable to inhibit mutant EGFR especially after acquired resistance to first-generation TKIs with T790M mutation. Acquired resistance mechanisms to AZD9291 need to be determined. EGFR C797S mutation was reported as one of the mechanisms [4-6]. Tress et al performed droplet digital PCR on serial cell-free plasma DNA specimens collected from fifteen AZD9291 treated subjects positive for T790M mutation before treatment and six cases acquired C797S mutation when resistance occurred [4]. Her2 or MET amplification might also be one of the diversity of resistance mechanisms when tested by NGS $[3,7]$. SCLC transformation accounted for acquired resistance to AZD9291 was seldom reported before. As more and more patients were treated with AZD9291, SCLC transformation as resistant mechanism to AZD9291 was also reported. In the article elucidating mechanisms of acquired resistance to AZD9291 by Kim et al in 2015, one patient was found as SCLC transformation [8]. And another two cases of small cell carcinoma transformation were also reported during AZD9291 treatment in 2016 [9]. Here we also reported a case of SCLC transformation after 6 months of AZD9291 treatment.

Small cell carcinoma transformation from NSCLC was reported in first-generation TKIs resistant cases and is accepted as one of acquired resistance mechanisms $[1,10]$. Sequist et al reported a rate of $11 \%$ of SCLC transformation in resistance to first-generation TKIs treatment [1], although the other reports were not this high. Neuron-specific tumor marker elevation might indicate the happening of transformation in some cases $[11,12]$. However, SCLC transformation accounts for acquired resistance to the third-generation TKIs was seldom reported. In our case, the patient's hepatic mass appeared after 6 months of AZD9291 treatment. And her NSE level was normal prior-AZD9291 treatment, and much higher than normal post-AZD9291 treatment when hepatic masses appeared. The NSE level also decreased dramatically after chemotherapy with SCLC regimen.

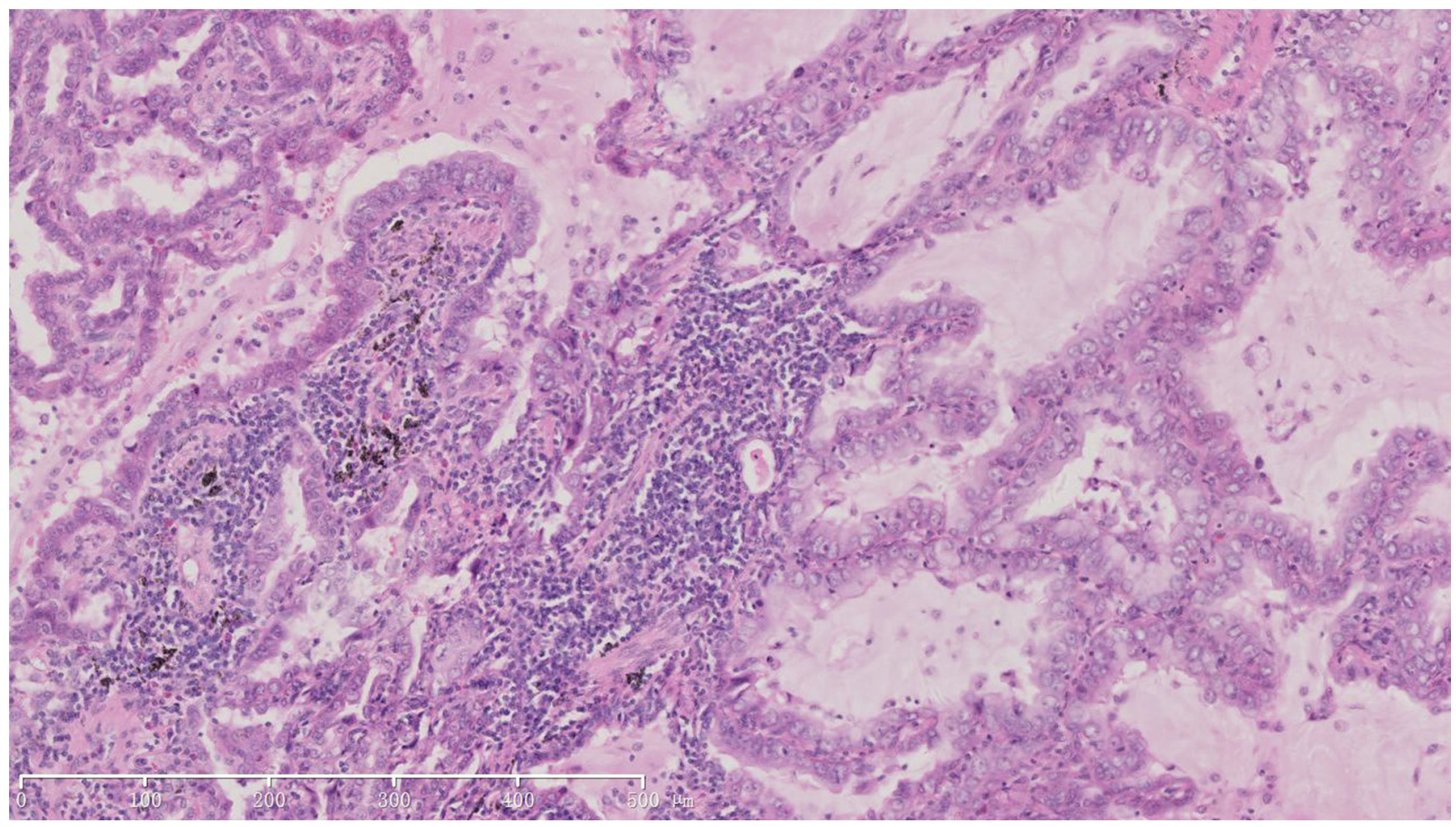

Figure 1: HE staining of surgical sample of lung showed histopathology of adenocarcinoma (X100). 

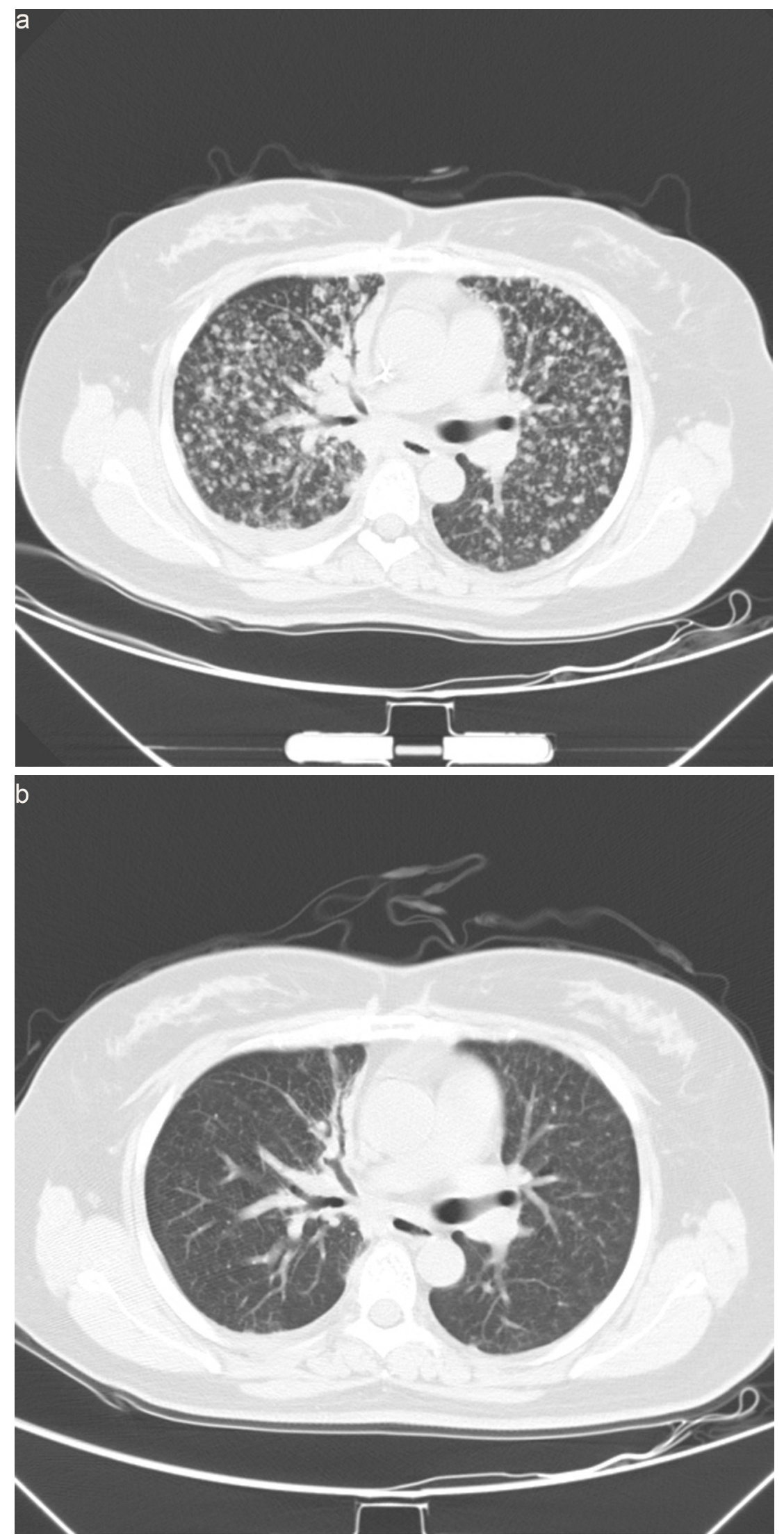

Figure 2: Computed tomography scan images of lung prior and post-AZD9291 treatment. a. Disease progressed in Dec,2015 after treatment of erlotinib and chemotherapy, prior-AZD9291. Patient had symptoms of cough and short of breath. b. Partial response after one month of AZD9291 treatment. Symptoms were much relieved. 

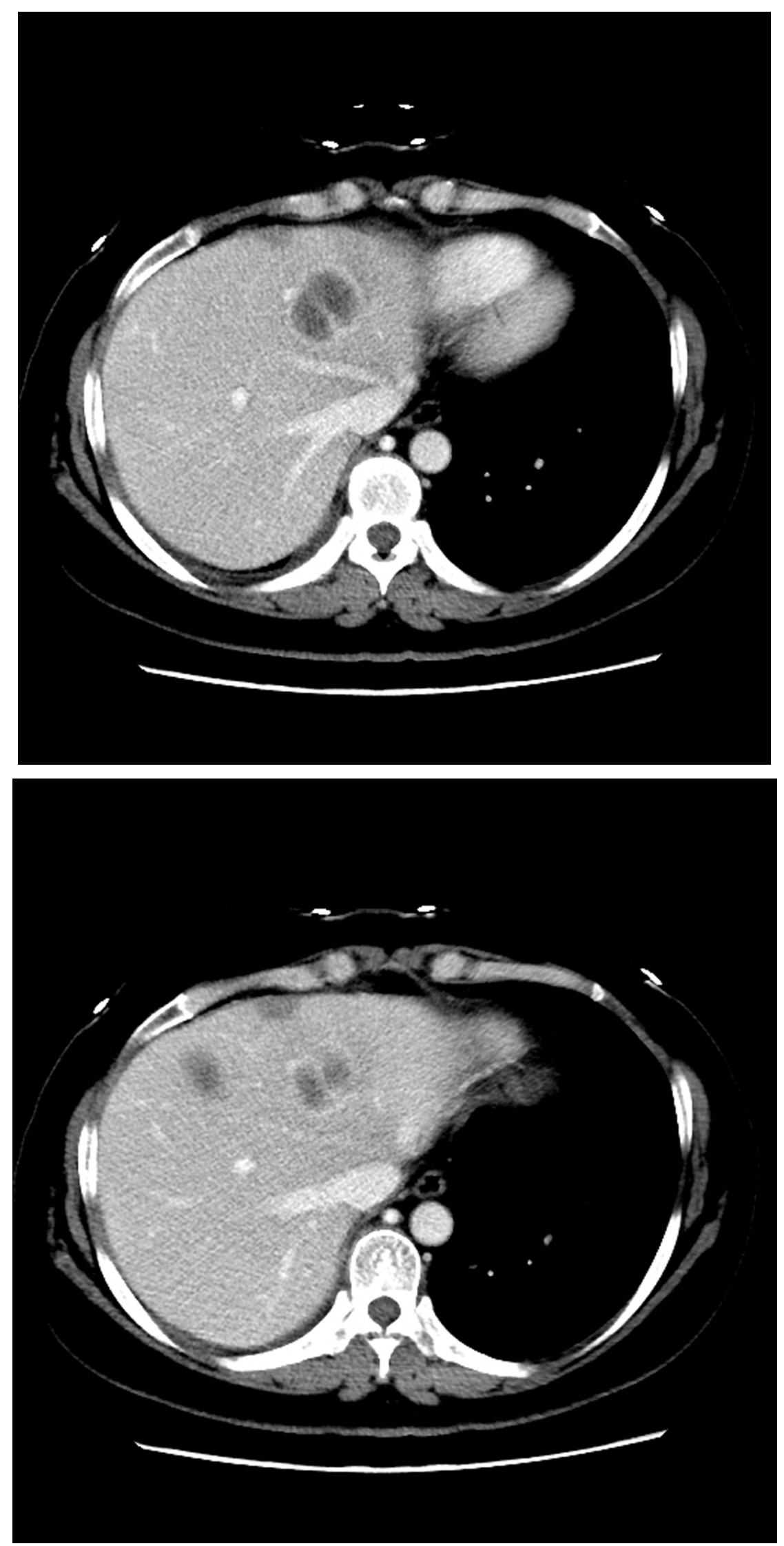

Figure 3: Computed tomography scan images showed new hepatic lesions appeared after 6 months of AZD9291 treatment. 
Our case also has several questions to debate. First, the patient's ctDNA was negative for T790M mutation, but finally she benefitted from treatment of AZD9291. We thought her negative T790M mutation might be a false test result because of the low sensitivity of ARMS in ctDNA detection. Her meanwhile negative exon19 deletion result helped to illustrate it. Oxnard et al explored in 102 patients with T790M-negative plasma using detection of TKI-sensitive EGFR mutation as a control for presence of tumor-derived circulating DNA. Patients with both negative T790M and sensitive mutation could achieve ORR as high as $64 \%$ of AZD9291 treatment, which meant a high possibility of false negative. Therefore, testing EGFR sensitive mutation in plasma may help to interpret negative plasma T790M [13]. Secondly, it was questioned whether the hepatic lesions were another primary liver small cell neuronendocrine carcinoma or a histological transformation? We thought it was a transformation because the NSE level was just elevated after AZD9291 treatment and re-biopsy pathology showed small cell carcinoma with EGFR exon19 deletion as well. This case also showed a rapid elevation of serum NSE level accompanied with tumor progression which may indicate SCLC transformation. Detection of persistent elevated NSE level might need attention during EGFR TKIs treatment. Peripheral ctDNA tested by NGS of this case showed mutations of P53, pTEN and PIK3CA. Our NGS detection confirm the previous finding that TP53 mutation accounts for approximately $86 \%$ in SCLC [14].

In summary, we deduce that small cell carcinoma transformation is the resistance mechanism to AZD929 for our case. We emphasized the importance of re-biopsy. Both histopathology and molecular test are meaningful, because it may provide more evidence for patient's precise treatment.

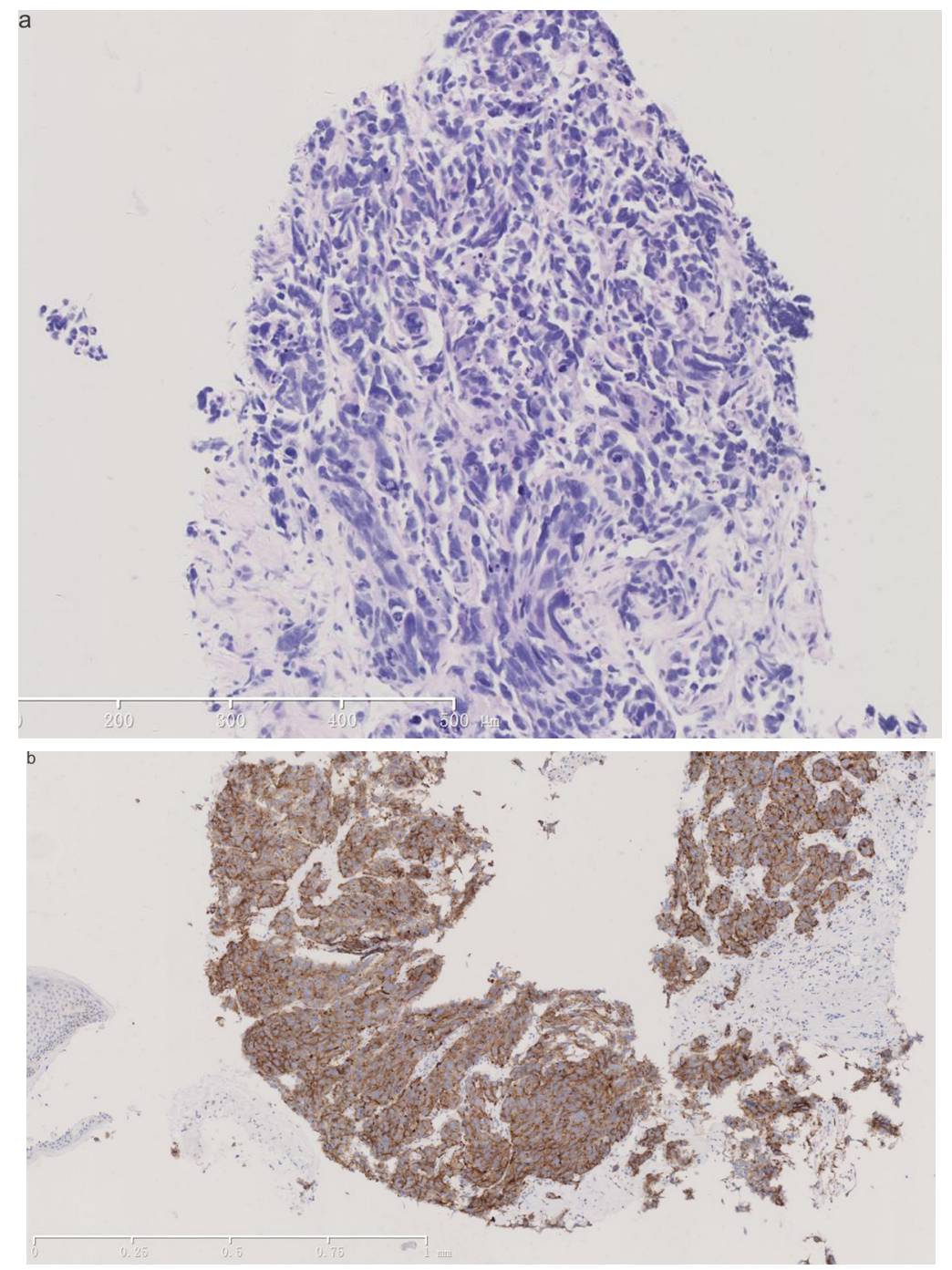

Figure 4: Pathological images of rebiopsy of hepatic mass.a. HE staining of hepatic mass post-AZD9291 showed small cell carcinoma transformation (X100). b. Immunohistochemical staining of hepatic mass post-AZD9291 showed strong synaptophysin staining $(+++)(\mathrm{X} 100)$. 


\section{CONFLICTS OF INTEREST}

The author(s) indicated no potential conflicts of interest.

\section{REFERENCES}

1. Sequist LV, Waltman BA, Dias-Santagata D, Digumarthy S, Turke AB, Fidias P, Bergethon K, Shaw AT, Gettinger S, Cosper AK, Akhavanfard S, Heist RS, Temel J, et al. Genotypic and histological evolution of lung cancers acquiring resistance to EGFR inhibitors. Sci Transl Med. 2011; 3: 75ra26.

2. Yu HA, Arcila ME, Rekhtman N, Sima CS, Zakowski MF, Pao W, Kris MG, Miller VA, Ladanyi M, Riely GJ. Analysis of tumor specimens at the time of acquired resistance to EGFR-TKI therapy in 155 patients with EGFR-mutant lung cancers. Clin Cancer Res. 2013; 19: 2240-7.

3. Janne PA, Yang JC, Kim DW, Planchard D, Ohe Y, Ramalingam SS, Ahn MJ, Kim SW, Su WC, Horn L, Haggstrom D, Felip E, Kim JH, et al. AZD9291 in EGFR inhibitor-resistant non-small-cell lung cancer. N Engl J Med. 2015; 372: 1689-99.

4. Thress KS, Paweletz CP, Felip E, Cho BC, Stetson D, Dougherty B, Lai Z, Markovets A, Vivancos A, Kuang Y, Ercan D, Matthews SE, Cantarini M, et al. Acquired EGFR C797S mutation mediates resistance to AZD9291 in nonsmall cell lung cancer harboring EGFR T790M. Nat Med. 2015; 21: 560-2.

5. Yu HA, Tian SK, Drilon AE, Borsu L, Riely GJ, Arcila ME, Ladanyi M. Acquired Resistance of EGFR-Mutant Lung Cancer to a T790M-Specific EGFR Inhibitor: Emergence of a Third Mutation (C797S) in the EGFR Tyrosine Kinase Domain. JAMA Oncol. 2015; 1: 982-4.

6. Niederst MJ, Hu H, Mulvey HE, Lockerman EL, Garcia AR, Piotrowska Z, Sequist LV, Engelman JA. The Allelic Context of the C797S Mutation Acquired upon Treatment with Third-Generation EGFR Inhibitors Impacts Sensitivity to Subsequent Treatment Strategies. Clin Cancer Res. 2015; 21: 3924-33.
7. Ou SH, Agarwal N, Ali SM. High MET amplification level as a resistance mechanism to osimertinib (AZD9291) in a patient that symptomatically responded to crizotinib treatment post-osimertinib progression. Lung Cancer. 2016; 98: 59-61.

8. Kim TM, Song A, Kim DW, Kim S, Ahn YO, Keam B, Jeon YK, Lee SH, Chung DH, Heo DS. Mechanisms of Acquired Resistance to AZD9291: A Mutation-Selective, Irreversible EGFR Inhibitor. J Thorac Oncol. 2015; 10: 1736-44.

9. Ham JS, Kim S, Kim HK, Byeon S, Sun JM, Lee SH, Ahn JS, Park K, Choi YL, Han J, Park W, Ahn MJ. Two Cases of Small Cell Lung Cancer Transformation from EGFR Mutant Adenocarcinoma During AZD9291 Treatment. J Thorac Oncol. 2016; 11: e1-4.

10. Oser MG, Niederst MJ, Sequist LV, Engelman JA. Transformation from non-small-cell lung cancer to smallcell lung cancer: molecular drivers and cells of origin. Lancet Oncol. 2015; 16: e165-72.

11. Zhang Y, Li XY, Tang Y, Xu Y, Guo WH, Li YC, Liu XK, Huang CY, Wang YS, Wei YQ. Rapid increase of serum neuron specific enolase level and tachyphylaxis of EGFRtyrosine kinase inhibitor indicate small cell lung cancer transformation from EGFR positive lung adenocarcinoma? Lung Cancer. 2013; 81: 302-5.

12. Watanabe S, Sone T, Matsui T, Yamamura K, Tani M, Okazaki A, Kurokawa K, Tambo Y, Takato H, Ohkura N, Waseda Y, Katayama N, Kasahara K. Transformation to small-cell lung cancer following treatment with EGFR tyrosine kinase inhibitors in a patient with lung adenocarcinoma. Lung Cancer. 2013; 82: 370-2.

13. Oxnard GR, Thress KS, Alden RS, Lawrance R, Paweletz CP, Cantarini M, Yang JC, Barrett JC, Janne PA. Association Between Plasma Genotyping and Outcomes of Treatment With Osimertinib (AZD9291) in Advanced NonSmall-Cell Lung Cancer. J Clin Oncol. 2016; 34: 3375-82.

14. Dowlati A, Lipka MB, McColl K, Dabir S, Behtaj M, Kresak A, Miron A, Yang M, Sharma N, Fu P, Wildey G. Clinical correlation of extensive-stage small-cell lung cancer genomics. Ann Oncol. 2016; 27: 642-7. 